\title{
La televisión en fin de año y los especiales de humor de José Mota. Imitaciones y parodias para relatar la actualidad y la COVID-19 desde la comedia
}

Urte amaierako telebista eta José Mota umorezko saio bereziak. Imitazioak eta parodiak komediatik gaurkotasuna eta COVID-19a kontatzeko

New Year's Eve television and José Mota’s humor specials. Imitations and parodies to relate current affairs and COVID-19 from comedy

\author{
Patricia Gascón-Vera \\ Universidad de Zaragoza
}

RESUMEN: El último día del año, la programación televisiva se adapta. Durante los últimos treinta años, en TVE los humoristas se han hecho cargo del especial previo a las campanadas. Concretamente, José Mota lo ha liderado veinte ocasiones, la mitad en solitario, con alta repercusión de audiencia, pero poca profusión académica. Por ello, se contrasta su guion con las preocupaciones sociales del CIS y sus características estructurales desde un análisis de contenido comparativo sobre sus dos últimas emisiones, 2019 y 2020. Cotejo que arroja que su escaleta aborda, pero no de forma mayoritaria, el paro, la política o el COVID-19 desde imitaciones y parodias.

PALABRAS CLAVE: Televisión; humor; programación; formato; análisis de contenido; COVID-19.

ABSTRACT: On the last day of the year, television programming adapts. During the last thirty years, on TVE comedians have taken charge of the special before New Year's Eve. Specifically, José Mota has led it twenty times, half alone, with a high audience impact, but little academic profusion. For this reason, its script is contrasted with the social concerns of the CIS and its structural characteristics from a comparative content analysis of its last two broadcast formats, 2019 and 2020. A comparison that shows that its rundown addresses, but not in a majority way, unemployment, politics or COVID-19 from imitations and parodies.

KEYWORDS: Television; humor; programming; format; content analysis; COVID-19.

\footnotetext{
* Correspondencia a / Corresponding author: Patricia Gascón-Vera. Universidad de Zaragoza, calle de Pedro Cerbuna, 12 (50009 Zaragoza) - patriciagascon@unizar.es - https://orcid.org/0000-0002-8516-3225

Cómo citar / How to cite: Gascón-Vera, Patricia (2021). «La televisión en fin de año y los especiales de humor de José Mota. Imitaciones y parodias para relatar la actualidad y la COVID-19 desde la comedia», Zer, 26(51), 139-162. (https://doi.org/10.1387/zer.22529).

Recibido: 9 febrero, 2021; aceptado: 25 junio, 2021.

ISSN 1137-1102 - eISSN 1989-631X / (c) 2021 UPV/EHU

(c) (i) $(\Theta)$ Esta obra está bajo una Licencia

(c) Creative Commons Atribución-NoComercial-SinDerivadas 4.0 Internacional
} 


\section{Introducción}

Los formatos de televisión programados para el último día del año han sido generalmente galas y/o especiales dedicados al humor ligado a la actualidad y, concretamente en los últimos años, a la figura de José Mota, humorista por excelencia vinculado a este tipo de contenidos. Siendo el de 2020-2021 el vigésimo primer programa que protagoniza para el ente público TVE.

«La televisión se basa en la repetición de modelos de éxito, lo que suele dejar un margen muy escaso para la innovación», dice León (2008: 21). Pese a esa falta de innovación, es cierto que su gran vinculación y renovación justifica la elección como foco de estudio de esta opción programática, junto con los notables resultados de audiencia que ha obtenido históricamente, tanto el especial de humor abordado, como sus formatos posteriores que en 2020-2021 han batido el récord histórico de consumo de televisión durante las doce campanadas con 22,3 millones de espectadores (Barlovento Comunicación, 2021).

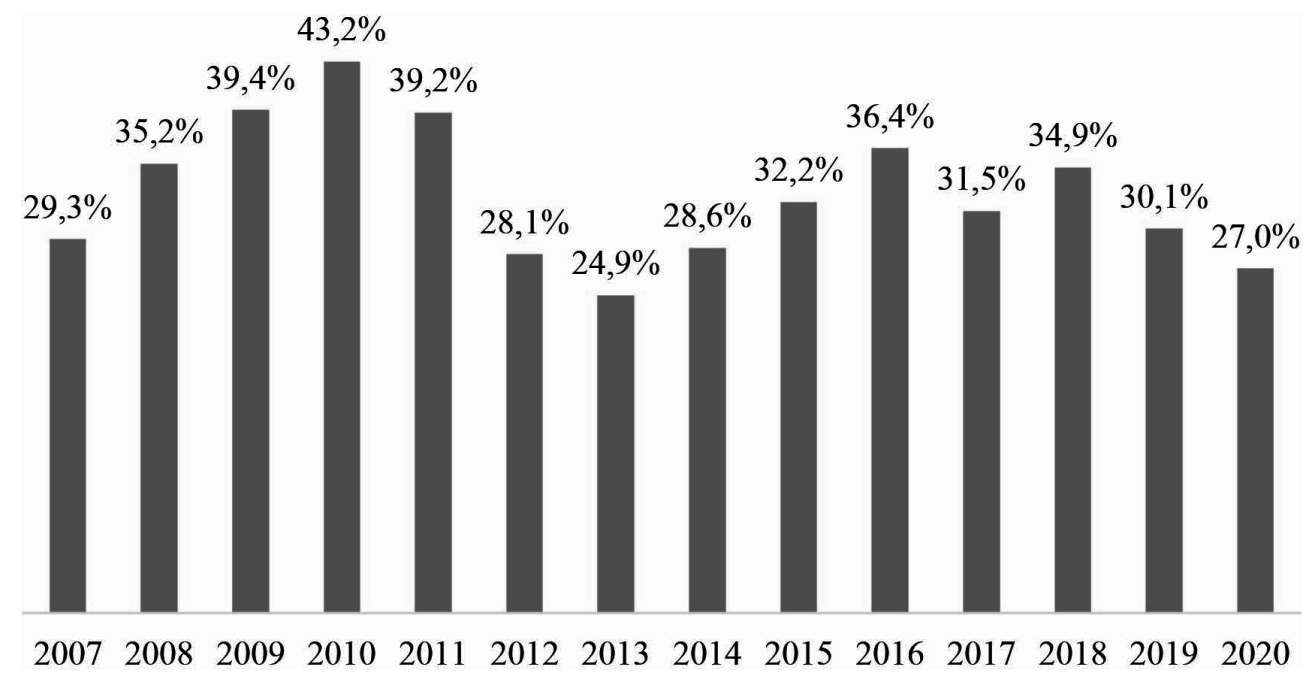

Fuente: Kantar media, Barlovento Comunicación y Rtve.es.

GrÁfICO 1

Índice de audiencia registrada por los últimos especiales de humor en TVE

Tras estos datos contextuales, en el transcurso de la investigación se repasa la programación en TVE en materia de humor, los principales exponentes nacionales y cómo ha sido históricamente la parrilla de la cadena pública en lo referente a los especiales fin de año. Un estudio que se articula desde un análisis de contenido sobre 
la estructura y los temas tratados de forma comparativa de los dos últimos formatos creados por José Mota para la última noche del año.

El humor, de la mano de la información y la actualidad, es un material sobre el que es dificil generar taxonomías por «la versatilidad y el dinamismo de las fórmulas» (Gordillo, 2009: 244). Es un recurso constante en la programación y que ha generado diferentes análisis. García-Avilés (2004) determina el pseudoperiodismo satírico y periodismo de entretenimiento y Valhondo se refiere a la infosátira (2007) y la sátira televisiva (2011). Línea en la que se encuentra la denominación periodismo de humor que pone en valor la labor periodística que se realiza en estos proyectos audiovisuales (Gascón-Vera, 2019: 141), el humor televisivo de Aguilera (2019) o Méndez (2004: 163) que se refiere a programas humorísticos de tipo informativo donde el humor basado en actualidad no busca solo la risa, sino una reacción reflexiva.

Amparados todos estos avances, además, en estudios de caso de formatos concretos (Carpio, 2008; Arroyo, 2008; San José, 2008; Gascón-Vera, 2019). Pese a este corpus académico, los especiales de humor de fin de año no han sido atendidos de forma específica, siendo esta la principal justificación de la investigación; es decir, su originalidad, defendida bajo los avances de las referidas obras sobre infoentretenimiento y humor. De tal forma, que se considera una opción programática insuficientemente revisada y con escasas aproximaciones como la de Cuenca-Piqueras y Moreno (2018) sobre imagen femenina durante las campanadas.

Por todo ello, la pretensión es conocer si estos dos ejemplos versan sobre la actualidad y, en referencia a la situación actual, cómo ha afectado el COVID-19 a los contenidos. Ambas ideas fluctúan sobre dos investigaciones previas en las que se conoció el proceso de creación del primer formato (Gascón-Vera y Torres, 2020) y unas primeras consecuencias de cómo el humor en televisión ha narrado la pandemia (Bonaut y Gascón-Vera, 2020) desde El Intermedio (La Sexta, 2006) y sus vídeos manipulados, un hecho que incluso ha variado la producción de los formatos (Andueza, Santana y de Luis Otero, 2020).

Por lo tanto, este artículo se adscribe en un prisma reciente de investigación, aunque prolijo, sobre el que partimos de Sola-Morales (2020) y su análisis de memes digitales sobre la COVID-19 en España que ha servicio de base metodológica, como se comprobará en siguientes páginas. Conformando pues parte de una nueva línea de trabajo que prevé explorar el uso del humor durante el período confinamiento causado por la pandemia del coronavirus y en el que se ha revisado su tratamiento internacional desde Torres et al. (2020), Balarezo-López (2020) y los memes virales en Perú como modo de enfrentar la adversidad con humor, en Ecuador (Mancero, Naranjo y Parreño, 2020), Jordania (Hussein y Aljamili, 2020) o Italia (Amici, 2020) desde donde se advierte una de las principales cualidades del humor, su efecto dis- 
tanciador y emocional gracias a su comicidad y sus técnicas de la ansiedad lo que le convierte en una herramienta de comunicación que permite reinterpretar su significado.

\section{Marco teórico: programación, televisión y humor}

\subsection{Programación televisiva}

La programación en televisión es una actividad profesional que aspira a conseguir audiencia y que está delimitada por el momento de la emisión, sus franjas, el género y la innovación. Se trata de un campo de investigación de los Television Studies que comprende a los programas — unidades audiovisuales con inicio y final- $\mathrm{y}$ a los formatos - estructuras con nombre propio y características reincidentes- que pueden visionarse por los espectadores en una parrilla televisiva, es decir, junto con un grupo de formatos seleccionados por día, franja de emisión, temática y cadena. Un ámbito estudiado por Prado y Delgado (2010), Arana (2011) o Contreras y Palacio (2003: 13) que definen como «la base de la actividad económica de la televisión», cuyo propósito es atraer la atención del público de forma mayoritaria y mantenida, también influida por las decisiones de los grupos, productoras y competencia televisiva (Sebastián, 2011).

De su análisis general, nos adscribimos a la cadena objeto de estudio: TVE. Quintas-Froufe (2018) o Roel (2014) han conocido las particularidades de su audiencia desde la que parten otro tipo de estudios temáticos como sobre series cómicas, su programación deportiva o infantil y juvenil (Diego y Grandío, 2014; Bonaut, 2008 y Fernández Gómez, 2012). Además de estudios de caso como la programación sensacionalista de "Corazón»(Romero-Rodríguez, Moreno y Toukoumidis, 2015) o «Estudio 1» (Merchán, 2014).

Por lo tanto, en este marco, se comprueba que los acercamientos a la programación referidos a un género y/o programa son una tendencia del ámbito académico de los Television Studies, como lo es TVE debido a su preeminencia como primera cadena existente en nuestro país.

\subsection{ESTUdio Del HUMOR EN TELEVISión}

Pinto (1991: 9) recoge las palabras de Bergson (1973): «Todo lo humorístico es propiamente humano». «Igualmente, la experiencia de lo cómico es universal» dice Berger (1999: 15) y, además, sirve para reflejar las características de cada cultura (Sánchez, 2010: 3). Se estima que el humor es algo más, argumento que sostiene Fernández Flórez (1945): «El humor es — sencillamente— una posición ante 
la vida». Y es que el humor no se adscribe solo a la risa, sino a la reflexión y puede trasladarse desde la información de un medio de comunicación, también la televisión, asevera Contreras (2008: 21), para quien «el éxito del humor en televisión no es más que el reflejo de lo que representa en la vida cotidiana». Gordillo va más allá y atisba que «es uno de los principales componentes de la televisión» (2009: 13).

Para determinar los programas que aúnan información y humor, se parte de su encuadre del infoentretenimiento (Krüger, 1988) una «tendencia audiovisual que aúna información y entretenimiento en diferentes formatos televisivos» (Aguilera, 2019: 32) y de relevancia en el periodismo actual, tanto a escala internacional y nacional, con especial importancia en la televisión (Redondo y Campos-Domínguez, 2015: 74).

Bajo esta tendencia, al igual que Arroyo (2008: 173-177) los programas pueden enmarcase en el género televisivo de "vocación híbrida» infoshow y, dentro de sus posibilidades en los infoshow de imitaciones, programas que usan «la actualidad como punto de partida, la parodian mediante imitadores que «clavan» a conocidos personajes para recrear, desde la distancia humorística, situaciones conflictivas acontecidas a lo largo de la semana». Un contenido constitutivo al entretenimiento que «se materializa con entidad propia en los programas concebidos para suscitar la risa o la carcajada en el espectador» (Pedrero, 2008: 42).

Asimismo, aunque partimos de esta consideración, se aporta la diferenciación de Luzón y Ferrer (2008: 143) de que cuando el entretenimiento forma parte de la información se habla de infoshow, siendo pues un resultado del tratamiento de las noticias, mientras que, a la inversa, cuando la información pasa a formar parte del entretenimiento es infoentertainment el que, como completa Salgado (2010: 61), es un cambio de registro en el que el periodismo «cede terreno» al tono humorístico. El cual puede ser establecido en un amplio arco de recursos como la parodia, ampliamente señalada en esta contribución y que Carpio (2008: 40) define como «imitación burlesca» omnipresente en la cultura actual que remite a una obra anterior, la que debe de ser conocida por los receptores para que se genere una comunicación eficaz. Y que, asimismo, se completa con otras figuras humorísticas como la pantomima, la ironía, el chiste, la sátira o la caricatura, tal y como presentan los últimos autores.

\subsubsection{Humor en TVE y exponentes del sketch en España}

TVE comenzó sus emisiones en octubre de 1956, tras una etapa convulsa, en una dictadura y con un escueto panel de receptores. Desde ese momento, "cuando la televisión era tan solo un proyecto, el entretenimiento ocupó un lugar destacado» (Guerrero, 2010: 36) gracias a programas de variedades como «Club del sábado» 
(1958-1959). De tal forma que el entretenimiento «formó parte de la programación desde el inicio de sus emisiones» siendo el 65\% de la difusión programática franquista (Antona, 2017: 31-34). Y es que en 1992 ya se habían emitido más de sesenta programas humorísticos (Pedrero, 2008: 42).

A continuación, en el ya referido estudio de Méndez (2004) se atestigua que el humor comenzó como parte de los programas de variedades «Noche de fiesta» o concursos «Un, dos, tres, responda otra vez» que dieron forma a figuras mediáticas como Gila o Tip y Coll. Hasta que, con la llegada de las privadas, en los años noventa, el humor se desarrolló con el primer late show «Esta noche cruzamos el Mississippi» (Telecinco, 1995-1997), programas satíricos de corazón «Qué me dices» (1995-1998) y políticos «Caiga quien caiga» (1996-2007) (Cascajosa, 2016: 60-61). Los que se unirían a nuevas propuestas a mediados de los 2000 como «Noche Hache» (Cuatro, 2005-2008) y «Buenafuente» (2005-2011).

Adscribiéndonos a la tipología de sketches, en España, algunos formatos reseñables han sido «Splunge» (La 1, 2005), «Latrevisión» (Telecinco, 2005), «Homo Zapping» (Antena 3, 2003-2007; Neox 2017-2018), "Made in China» (La 1, 2005), "Agitación+IVA» (Telecinco 2005-2006), «Miré Usté» (Antena 3, 2005-2006), «Sé lo que hicisteis» (La Sexta, 2006-2001), «Muchachada Nui» (La 2, 2007-2010) o «iY ahora qué?» (La 1, 2009), tal y como detallan Pedrero (2008: 43) y Diego y Grandío (2011: 58).

En este sentido, el sketch también tiene un gran desarrollo en formatos autonómicos como «Vaya Semanita» (ETB, 2003-2016), «Oregón TV» (Aragón TV, 2008-) y «Polònia» (TV3, 2006-), caracterizados, al mismo tiempo, por la imitación y la parodia de políticos y personajes de la sociedad, así como por la actualidad en sus contenidos (Gascón-Vera y Marta-Lazo, 2018: 211). Por lo tanto, se vislumbra que los programas de humor que incluyen sketches e imitaciones con referencias a la información y a la actualidad han formado parte de la programación española, al igual que de forma internacional con «Saturday Night Live» (NBC, 1975-) o «Little Britain» (BBC, 2003).

Recientemente, este tipo de contenido está teniendo su traslación a redes sociales como YouTube con programas específicos, «Pantomima Full» y «Living Postureo», y desde formatos de cadenas de pago como «La Resistencia» (\#0, 2018-) (Aguilera, 2020) que exponen parte de sus contenidos de forma abierta a través de estos agregadores o de historias de Instagram (Gascón-Vera, 2020). Configurándose, de este modo, Internet como una vía potencial para que el sketch y los espacios cómicos encuentren a su público. Otro ejemplo de relevancia de contenido humorístico sería el caso de los doblajes paródicos en YouTube, constatado por Trabadela-Robles y Corral-Motino (2021: 21) a través de creadores como Loulogio o Desahogada desde los que confieren que se adaptan a esta plataforma ofreciendo 
«contenido original» $\mathrm{y}$ «potencialmente viral» enfocado al gran público, sin recurrir a medios de masas como la televisión.

En definitiva, YouTube es una ventana más para el consumo no lineal en la que, en el caso que nos ocupa, los sketches de José Mota también son ampliamente consumidos y difundidos, tanto desde la plataforma a la carta de RTVE como desde los canales del artista, donde destaca la repercusión de los especiales de Navidad. Su último proyecto, foco de esta investigación, en marzo de 2021, sumaba casi 778.000 visualizaciones, siendo ampliamente superado por las 262.346 reproducciones del año anterior ${ }^{1}$.

\section{Análisis histórico, fin de año con humor}

Desde que en 1978 TVE empezó las galas de fin de año, Nochevieja en la televisión pública siempre ha tendido a ser cosa de dos: Pajares y Esteso hicieron una 1979 Tip y Coll hicieron dos (1981 y 1982), pero Martes y Trece sentaron cátedra con los especiales Nochevieja ¡hola, hola, 89! Fue el primero de nueve programas llenos de sketches, tics y señores disfrazados de mujer que les convirtieron en un fenómeno cómico (...). (Buenafuente, 2011, pp. 120-121)

De 1989 a 1997, Martes y Trece protagonizaron ocho especiales, corregimos la cita anterior, porque en 1993 lo realizó Cruz y Raya. Ambos dúos consagraron su humor, el que expandían en sus formatos semanales, en este tipo de especiales caracterizados por sus personajes y sketches que han forjado parte de la historia de la programación humorística de España.

Cruz y Raya debutaron en «Pero esto ¿qué es?» (La 1, 1989-1991) y colaboraron en «Tutti frutti» (Telecinco, 1990-1992) hasta protagonizar «Nochebuena 1992». Con sus ideas e imitaciones crearon formatos propios «Abierto por vacaciones (1993)», «Estamos de vuelta (1995 y 1996)», «Este no es el programa de los viernes (1998)», «Estamos en directo (1999-2000)», «Cruz y Raya.com (2000-2004)» y «Juan y José Show» hasta su separación en 2007. Sus personajes Bartolo, El gitano Juan de Dios, Los vigilantes de la playa o La Blasa junto con muletillas e imitaciones donde empezaron a incorporar a famosos y actuaciones musicales en sus números» (Casado, 2017: 241) fueron los ingredientes de su humor que continuaron exponiendo en sus especiales de fin de año. Desde 1999 a 2006 como dúo y desde 2007 por José Mota, a excepción de 2012 y 2013 por Josema Yuste y Los Morancos.

\footnotetext{
1 Canal de YouTube José Mota https://www.youtube.com/channel/UCPCJV3XMMmdQ6ZJ4JPCf2jQ
} 
TABLA 1

Listado de especiales de Nochevieja emitidos en TVE desde 1988 a 2020

\begin{tabular}{|c|c|c|}
\hline Año & Humorista(s) & Título \\
\hline 1988 & Javier Gurruchaga & La última cena... del 88 \\
\hline 1989 & \multirow{4}{*}{ Martes y Trece } & A por uvas \\
\hline 1990 & & ¡Venga el 91! \\
\hline 1991 & & El 92 cava con todo \\
\hline 1992 & & Martes y Trece en directo \\
\hline 1993 & Cruz y Raya & Este año, Cruz y Raya... ¡seguro! \\
\hline 1994 & \multirow{4}{*}{ Martes y Trece } & ¡Fíjate! \\
\hline 1995 & & A Belén pastores \\
\hline 1996 & & Emisión imposible \\
\hline 1997 & & Adós \\
\hline 1998 & Los Morancos & Aligera y pon ya, La Primera \\
\hline 1999 & \multirow{8}{*}{ Cruz y Raya } & En efecto 2000 \\
\hline 2000 & & 2001, aunque sea en el espacio \\
\hline 2001 & & La verbena de la peseta \\
\hline 2002 & & Al $2003 \ldots$ sí hay que ir se va \\
\hline 2003 & & Regreso al 2004. El día del fin del año \\
\hline 2004 & & Érase una vez... 2004 \\
\hline 2005 & & $2005 \ldots$ repaso al futuro \\
\hline 2006 & & 2006... Perdiendo el Juicio: Operación maletín \\
\hline 2007 & \multirow{5}{*}{ José Mota } & Ciudadano Kien \\
\hline 2008 & & Es bello vivir \\
\hline 2009 & & Con el vértigo en los talones \\
\hline 2010 & & ¿¿Estamos contentos?! \\
\hline 2011 & & Seven: Los siete pecados capitales de provincia \\
\hline 2012 & Josema Yuste & Hotel 13 estrellas, 12 uvas \\
\hline 2013 & Los Morancos & La puerta del tiempo \\
\hline 2014 & \multirow{7}{*}{ José Mota } & Un país de cuento \\
\hline 2015 & & Resplandor en la Moncloa \\
\hline 2016 & & Operación And The Andarán \\
\hline 2017 & & Bienvenido Mister Wan-Da \\
\hline 2018 & & Retratos salvajes \\
\hline 2019 & & 31-D: Un golpe de Gracia \\
\hline 2020 & & Adiós dos mil vete, Cinema paraeso. \\
\hline
\end{tabular}

Fuente: elaboración propia. 


\subsection{José Mota y los especiales De HUMOR 2019 Y 2020}

El especial 2019 relata cómo un grupo de cómicos, denominados «Comité cómico nacional» — bajo la parodia del intento de Golpe de Estado del 23F- quieren instaurar una república cómica desde la cual perseguir «la seriedad», en el que se ironiza sobre los límites del humor, junto con el sarcasmo y la imitación. Este especial «arrasó en audiencia», tal y como refleja El Mundo (Gordillo, 2020) donde se traslada que superó al resto de opciones y llegó al 30\% y 3.963.000 espectadores, según Kantar Media (Bluper, 2020). Datos con los que TVE volvió a ser la cadena más vista en el último día del año en una programación que completó las Campanadas de Fin de Año.

En 2020 el share bajó al 27\% para Mota, pero obtuvo 4.598.000 espectadores (Barlovento Comunicación, 2020), un seguimiento que creció en TVE y sus posteriores campanadas hasta los 6.107.000 espectadores de audiencia media y el 29,3\% de cuota de pantalla. En este caso, se ayudó del clásico cinematográfico «Cinema Paradiso" (1988) para abordar la situación de un año convulso por la afección pandémica de la COVID-19 y desde el que mostrar un homenaje a los mayores como principales afectados de este virus.

\section{Objetivos, categorías de análisis y metodología}

El objetivo genérico es conocer la estructura y cómo aborda la actualidad desde el humor un formato programado en una fecha especial y con una presencia reiterativa a lo largo del tiempo, para lo que se parte de dos objetivos específicos desde los que derivan las preguntas de investigación:

- O1. Comprobar si ambos especiales, 2019 y 2020, incorporan en su guion los temas de actualidad, los cuales adscribimos a aquellos asuntos reflejados como principales problemas sociales por los ciudadanos, los que son delimitados gracias a los estudios del Centro de Investigaciones Sociológicas (CIS).

- O2. Descubrir si su estructura es variada en cuanto a recursos humorísticos y visuales.

- P1: ¿Cómo es la preponderancia de la actualidad en su guion y cuáles son los temas concretos asociados a dichos especiales?

- P2: ¿Cuáles son sus recursos humorísticos y visuales? ¿Cómo son sus escenografias, efectos y características propias?

Para lograr estas premisas, se traslada una aproximación descriptiva, interpretativa y comparativa desde el enfoque cualitativo. Al igual que Sola-Morales (2020) a través del estudio de caso, en el que se conviene como selección los especiales de 
humor de fin de año 2019 y 2020 en TVE, se efectúa la técnica del análisis de contenido para conocer estructura y elaborar tendencias desde las cifras de frecuencias.

Tras exponer la metodología aplicada, esta se apuntala en las palabras de Gibbs (2012: 189) sobre el análisis comparativo del que dice considera datos de los mismos entornos o grupos durante un periodo de tiempo para identificar similitudes y diferencias. También, desde la técnica de análisis de contenido de orientación empírica, exploratoria, vinculada a fenómenos reales y de finalidad predictiva como dice Krippendorff (1990: 10 y 31), ya que con ello se consigue al interpretar los datos como índices y síntomas de lo evidente. Superando el fin de conocer ciertos contenidos encontrando su sentido dentro del contexto (Díaz, 2018).

\section{TABLA 2}

Variables utilizadas en el análisis de contenido

\begin{tabular}{|c|c|c|c|c|}
\hline $\mathbf{N}$ & Escenario & Estructura de guion & Temas & Actores: número \\
\hline & \multirow[t]{2}{*}{$\begin{array}{l}\text { 1. Congreso real } \\
\text { 2. Congreso ficticio } \\
\text { 3. Croma } \\
\text { 4. Exterior } \\
\text { 5. Casa } \\
\text { 6. Plató estudio real } \\
\text { 7. Decorado } \\
\text { 8. Otro } \\
\text { 9. Cine }\end{array}$} & $\begin{array}{l}\text { 1. Parodia TV } \\
\text { 2. Parodia Cine } \\
\text { 3. Sketch } \\
\text { 4. Baile } \\
\text { 5. TV real } \\
\text { 6. Otros }\end{array}$ & $\begin{array}{l}\text { 1. Política } \\
\text { 2. Economía } \\
\text { 3. Sociedad } \\
\text { 4. Humor } \\
\text { 5. Otros }\end{array}$ & $\begin{array}{l}\text { 1. Uno } \\
\text { 2. Dos } \\
\text { 3. Tres } \\
\text { 4. Cuatro } \\
\text { 5. } 5 \text { a } 10 \\
\text { 6. Más de } 10 \\
\text { 7. Invitado } \\
\text { 8. No }\end{array}$ \\
\hline & & Descripción: & Tema concreto: & Quién participa: \\
\hline \multicolumn{2}{|c|}{ Imitación } & Recursos humorísticos & Recursos visuales & Otros aspectos \\
\hline \multicolumn{2}{|c|}{$\begin{array}{l}\text { 1. Sí } \\
\text { 2. No }\end{array}$} & $\begin{array}{l}\text { 1. Caracterización } \\
\text { 2. Chiste } \\
\text { 3. Ironía } \\
\text { 4. Otros } \\
\text { 5. Varios } \\
\text { 6. No }\end{array}$ & $\begin{array}{l}\text { 1. Música } \\
\text { 2. Canción doblada } \\
\text { 3. Doblaje } \\
\text { 4. Efectos especiales } \\
\text { 5. Rótulos } \\
\text { 6. He me rote ca / } \\
\text { imágenes reales } \\
\text { 7. Vídeo } \\
\text { 8. Otros } \\
\text { 9. Varios } \\
\text { 10. No }\end{array}$ & $\begin{array}{l}\text { Visual, efectos, temas, } \\
\text { etc. }\end{array}$ \\
\hline
\end{tabular}

Fuente: elaboración propia.

Para todo ello, se ha utilizado la siguiente tabla de codificación compuesta por ocho variables sobre aspectos estructurales (escenario, recursos humorísticos y visuales), así como los temas tratados y datos complementarios. Una estructura de análi- 
sis casada, asimismo, en aportaciones metodológicas previas (Gascón-Vera y Marta-Lazo, 2019) y en los elementos constructivos de la comedia de Martín-Sánchez (2020), de la que se comparten análisis de contenido y tema principal, análisis estructural y guion y análisis técnico con elementos sonoros: música; ambientales: escenografia y de postproducción: efectos visuales.

Por su parte, las variables de humor se centralizan en las categorías clásicas de Asa Berger (2017/2003) y en los análisis de humor y comunicación utilizados por Carpio (2008) en televisión, Pérez Pereiro (2007) en comedia y Meléndez-Malavé (2005) en prensa y humor.

Tras este proceso, en el primer especial se ha delimitado en 69 piezas y el segundo en 54 unidades a través de las que se ha codificado su contenido y estructura desde el programa estadístico SPSS. A este proceso, le ha continuado la correlación entre los temas de actualidad del guion y las principales cuitas de los españoles extraídas en las publicaciones del CIS consecuentes con las programaciones analizadas. Siendo este un proceso de investigación empleado por Gómez Rodríguez (2020) como acercamiento de investigación. De este modo, para poder ser conocida, la respuesta social ante la actualidad queda reflejada en la siguiente gráfica ordenada por importancia, según las respuestas estudiadas.

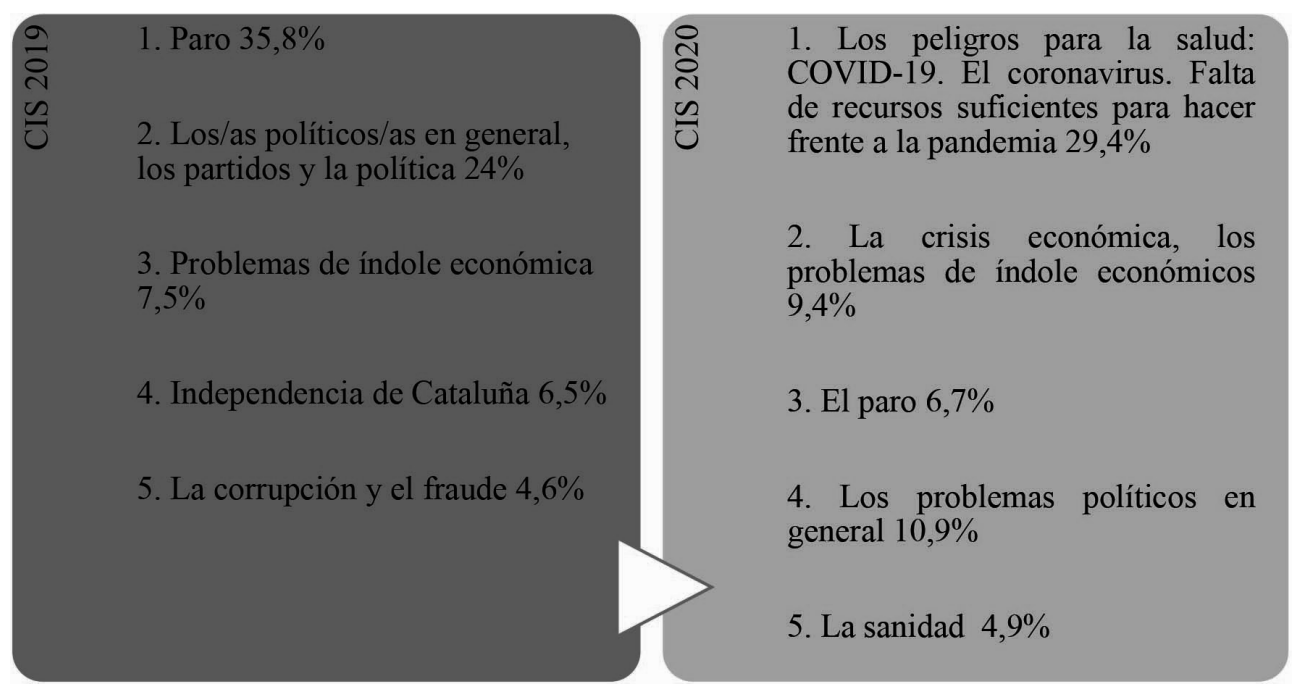

Fuente: CIS Barómetro octubre-noviembre (2019: 3) y CIS Barómetro noviembre (2020: 13).

FIGURA 1

Cinco principales resultados sobre el primer problema social en España 


\section{Resultados}

\subsection{AnÁlisis De estructura}

Para analizar los resultados partimos de la primera variable de estudio que delimita el tipo de escenario. En 2019 el empleo de croma ha sido predominante seguido del decorado del Congreso de los Diputados que registra el 19\%, casi mismo porcentaje que exteriores, ya que suma las grabaciones de sketches en el Congreso real, aunque en el caso 2020 el exterior supera el 20\% de los espacios.

Por lo tanto, se comprueba un mayor empleo de escenarios exteriores y, por tanto, reales, en el último formato. De igual forma, en ambos el croma es una de las soluciones mayoritarias y que la temática marca el escenario tanto con el Congreso, en sus dos posibilidades real y decorado, en 2019 como el cine en 2020.

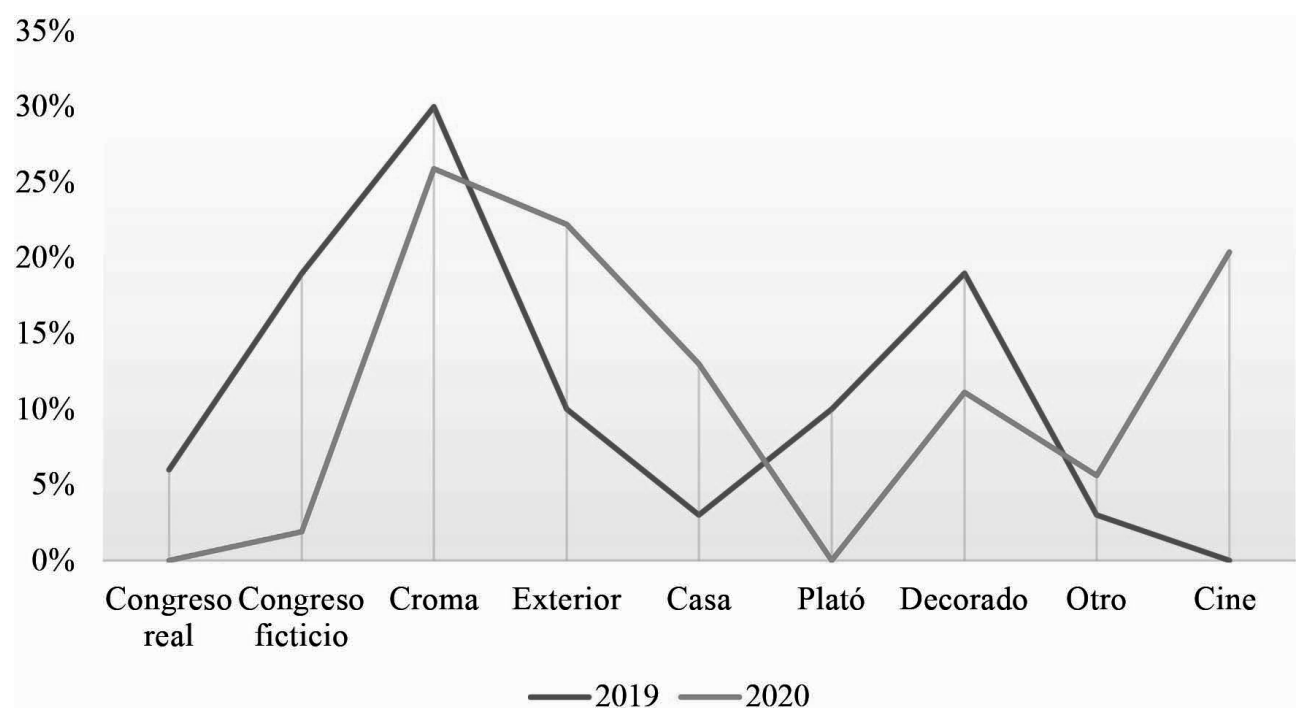

Fuente: elaboración propia.

\section{GrÁFICO 2}

Distribución de escenarios en los espacios de humor analizados

En cuanto a la distribución, en ambos se contempla una estructura pareja, más del 40\% de los espacios han sido sketches. Completado con las parodias, mayoritarias en 2020 con un 33\% de cine y 9\% de televisión, mientras que en 2019 el 22\% fue de la parodia de formatos de televisión y un 10\% estuvo dedicado a la parodia del cine. Porcentajes casi inversos que se complementan con un $9 \%$ y un $5 \%$ de bailes, respectivamente. 
Sobre los resultados de los asuntos principales de los espaciales, el tema fundamental del 2020 ha estado muy repartido entre las variables dispuestas y, como principal reseña, ha subido exponencialmente la categorización de «Otros» puesto que, aunque desde la comedia, el formato se estructuraba en el homenaje a los mayores. Una temática alejada de las categorías previstas previamente que se ha contabilizado en esta opción excluyente, pero igualmente distintiva. Una finalidad dirigida que se ha efectuado, además, desde la cobertura del COVID-19. Tras ese cometido, la política es el tema más recurrente, aunque la actualidad también se presenta de la mano de la economía y la sociedad, pero en escasa medida. Por su parte, en 2019 el humor fue el cometido fundamental, seguido muy de lejos por la política.

Al realizar una tabulación entre las variables tema y estructura, se conoce que, en 2019, la política, al igual que la economía, se trata fundamentalmente desde la parodia de programas de televisión y cine y por sketches. Parámetros que se repiten para los temas de sociedad, si bien la política es tratada en dos ocasiones por bailes. En el especial 2020 la parodia de cine concentra la actualidad desde la política, COVID-19, sociedad y economía, siendo los tres primeros representados, también, desde bailes.

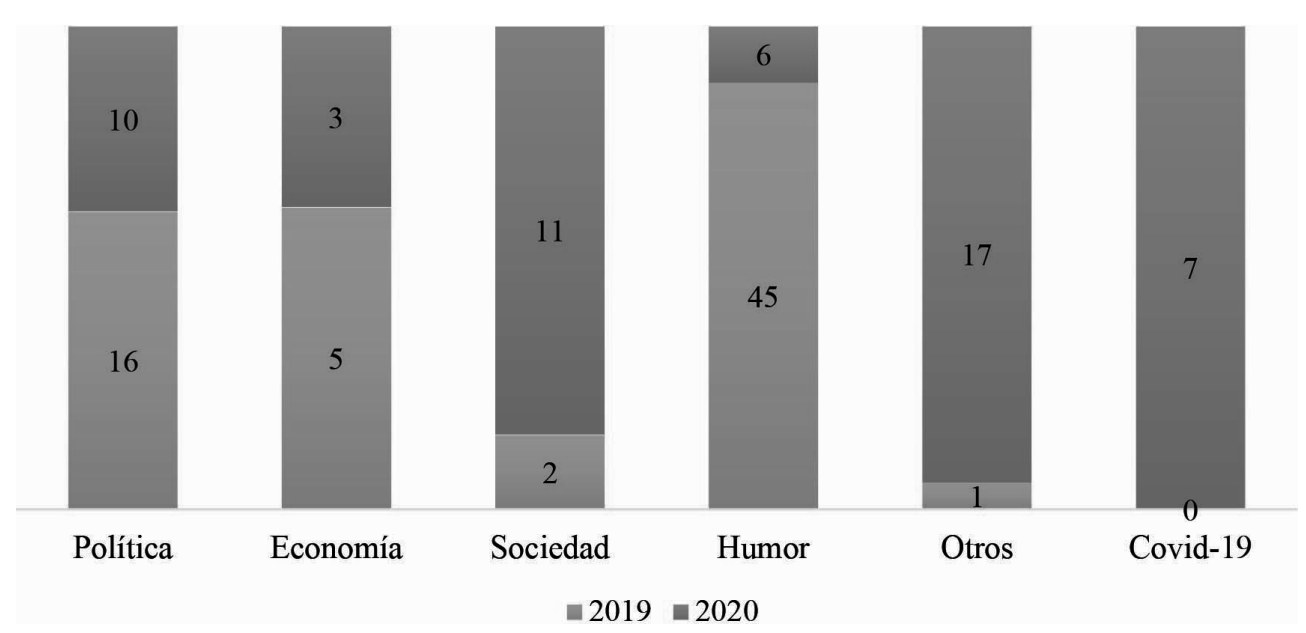

Fuente: elaboración propia.

GrÁfico 3

Distribución de temas según casos de aparición en los especiales 


\subsection{Tratamiento de la actualidad}

Al relacionar los aspectos concretos de actualidad reflejados por el especial con el interés de la ciudadanía testado gracias a los datos obtenidos por Informe CIS (2019) se puede observar una correlación. De la veintena de espacios que 2019 reflejaron un tema de actualidad de forma directa, se comprueba que la amplia mayoría corresponden con las inquietudes ciudadanas.

Al mismo tiempo, el resto de los temas se podrían delimitar en preocupaciones sociales que, aunque no recogidas por el índice CIS, sí pueden ampararse en la agenda setting de los medios como son el cambio climático, la libertad de expresión o la igualdad en el deporte. Misma realidad acaecida en 2020 con la igualdad racial, el discurso del odio, la situación del alquiler o el olvido social de la tercera edad en 2020. Por su parte, queda reflejado, casi en la mitad de los espacios de actualidad conformados en 2020 una referencia al COVID-19 tanto desde la crítica, la parodia o incluso imágenes reales de la pandemia como colofón.

TABLA 3

Temas abordados en relación con los problemas de la ciudadanía

\begin{tabular}{|c|c|c|c|}
\hline \multicolumn{2}{|l|}{ Especial 2019} & \multicolumn{2}{|l|}{ Especial 2020} \\
\hline $\begin{array}{l}\text { Inmigración irregular en México } \\
\text { Exportaciones españolas } \\
\text { Bomba nuclear Irán }\end{array}$ & $\begin{array}{r}3 \\
3 \\
-\end{array}$ & $\begin{array}{l}\text { Conflicto racial en EE.UU. } \\
\text { Censura }\end{array}$ & - \\
\hline $\begin{array}{l}\text { Juramento de los políticos } \\
\text { Compromiso político, relaciones entre polí- } \\
\text { ticos }\end{array}$ & $\begin{array}{l}2 \\
2\end{array}$ & $\begin{array}{l}\text { COVID-19, mascarillas } \\
\text { Estado de la sanidad }\end{array}$ & $\begin{array}{l}1 \\
5\end{array}$ \\
\hline Historia del humor & - & Izquierda política, pactos, corrupción & 4 \\
\hline Ventajas fiscales & $3 / 5$ & COVID-19, mascarillas & 1 \\
\hline El trabajo en España y funcionarios & 3 & Sanidad & 5 \\
\hline Boris Jonhson y el Brexit & 2 & Honradez en la política, robar & 4 \\
\hline Fake news y postverdad & 5 & Odio y crítica a las obras & - \\
\hline \multirow{3}{*}{$\begin{array}{l}\text { Política internacional Donald Trump } \\
\text { Conflicto político votaciones } \\
\text { Cambio climático }\end{array}$} & \multirow{3}{*}{$\begin{array}{r}2 \\
2 \\
-\end{array}$} & Deporte y explicaciones vacuas & - \\
\hline & & $\begin{array}{l}\text { Falsedad de los influencers } \\
\text { Falsa ayuda a los necesitados }\end{array}$ & - \\
\hline & & Exilio de Rey Emérito & - \\
\hline Paro e hipotecas en España & 1 & Efectos del COVID-19 & 1 \\
\hline Rebelión política & 2 & Implantes de pelo en Turquía & - \\
\hline
\end{tabular}




\begin{tabular}{|c|c|c|c|}
\hline \multicolumn{2}{|l|}{ Especial 2019} & \multicolumn{2}{|l|}{ Especial 2020} \\
\hline \multirow{2}{*}{$\begin{array}{l}\text { ERES, desempleo } \\
\text { Cargos políticos }\end{array}$} & \multirow{2}{*}{$\begin{array}{l}1 \\
5\end{array}$} & Abuso laboral y paro & 3 \\
\hline & & Alquileres turísticos & - \\
\hline \multirow{2}{*}{ Igualdad en el deporte } & \multirow{2}{*}{-} & Política y deslealtad de los partidos políticos & 4 \\
\hline & & COVID-19 y curva de contagios & 1 \\
\hline Sociedad ofendida, censura & - & $\begin{array}{l}\text { Vejez y falta de representatividad en la so- } \\
\text { ciedad }\end{array}$ & - \\
\hline \multirow{3}{*}{$\begin{array}{l}\text { Parlamento e investidura } \\
\text { Fallos del tren de Extremadura } \\
\text { Eléctricas en España y facturas } \\
\text { Sobre cualificación } \\
\text { Duración de la crisis económica } \\
\text { Paro y fin de mes }\end{array}$} & \multirow{3}{*}{$\begin{array}{l}2 \\
3 \\
1 \\
3 \\
1\end{array}$} & $\begin{array}{l}\text { Promesas incumplidas de la política } \\
\text { Bajar impuestos } \\
\text { Justicia independiente }\end{array}$ & $\begin{array}{r}4 \\
3 \\
- \\
\end{array}$ \\
\hline & & Políticos mediocres & 4 \\
\hline & & $\begin{array}{l}\text { Clase media amenazada } \\
\text { Explotación laboral } \\
\text { Evadir impuestos } \\
\text { Derechos sociales, fondos buitre }\end{array}$ & $\begin{array}{l}2 \\
3 \\
2 \\
2\end{array}$ \\
\hline Pactos políticos & 2 & Masturbación femenina & - \\
\hline \multirow{2}{*}{$\begin{array}{l}\text { Corona española } \\
\text { Cuatro elecciones en cuatro años }\end{array}$} & \multirow{2}{*}{$\overline{2}$} & Privatización y política en Madrid & 4 \\
\hline & & Pensiones & 2 \\
\hline Independencia de Cataluña & 4 & Presión inmobiliaria, fondos buitre & 2 \\
\hline Pago en negro & 3 & Carrera de las vacunas & 1 \\
\hline $\begin{array}{l}\text { Donald Trump } \\
\text { Libertad de expresión en la comedia }\end{array}$ & 2 & Vacuna & 1 \\
\hline Exilio político & 4 & $\begin{array}{l}\text { Homenaje a la tercera edad } \\
\text { COVID-19 }\end{array}$ & - \\
\hline
\end{tabular}

Fuente: elaboración propia.

\subsection{ReCURSOS HUMORÍsticos y VISUALES}

En cuanto a cuestiones de forma, en 2019 un 20\% de los espacios fueron protagonizados por un actor y hasta el $26 \%$ en 2020 y, en ambos, un $22 \%$ estuvieron realizados por dos actores. Por lo tanto, predominan los espacios protagonizados por entre uno o tres humoristas-actores, aunque se contabilizan exiguos espacios con más de diez protagonistas. Además, en el primer especial seis espacios están protagonizados por invitados, figura recurrente a lo largo del programa y no representativa en 2020 . 


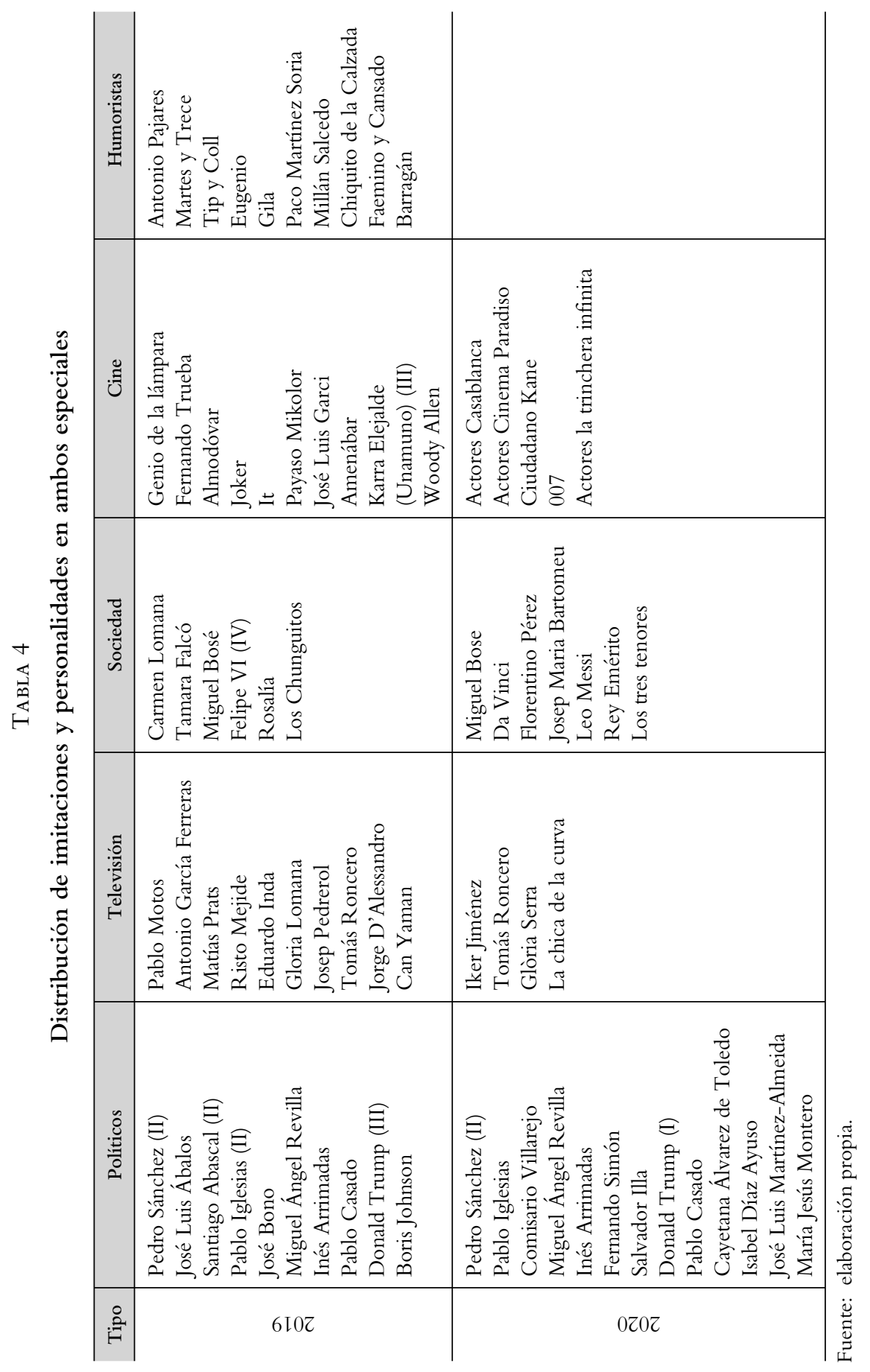


En materia de recursos, la preponderancia de imitaciones se comprueba en el $55 \%$ de los espacios, escasos casos menos que en 2020, aunque sí que la caracterización es una gran diferencia, ya que en el primer especial se contabiliza que un 52\% disponen de una o varias caracterizaciones, siendo el recurso más utilizado; mientras que en 2020 ha sido del 33\%. Por contrario, la ironía ha subido al 24\%, desde el $10 \%$ del año anterior.

Sobre esta idea, en 2019 se denotan caracterizaciones de políticos de todos los partidos con mayor representación en el Parlamento español, periodistas reconocidos, junto con directores, actores y personajes vinculados a la presente temporada, así como personajes de vigencia, con especial mención al Rey Felipe VI. En 2020, los políticos también sobresalen sobre otros sectores que aparecen de forma semejante.
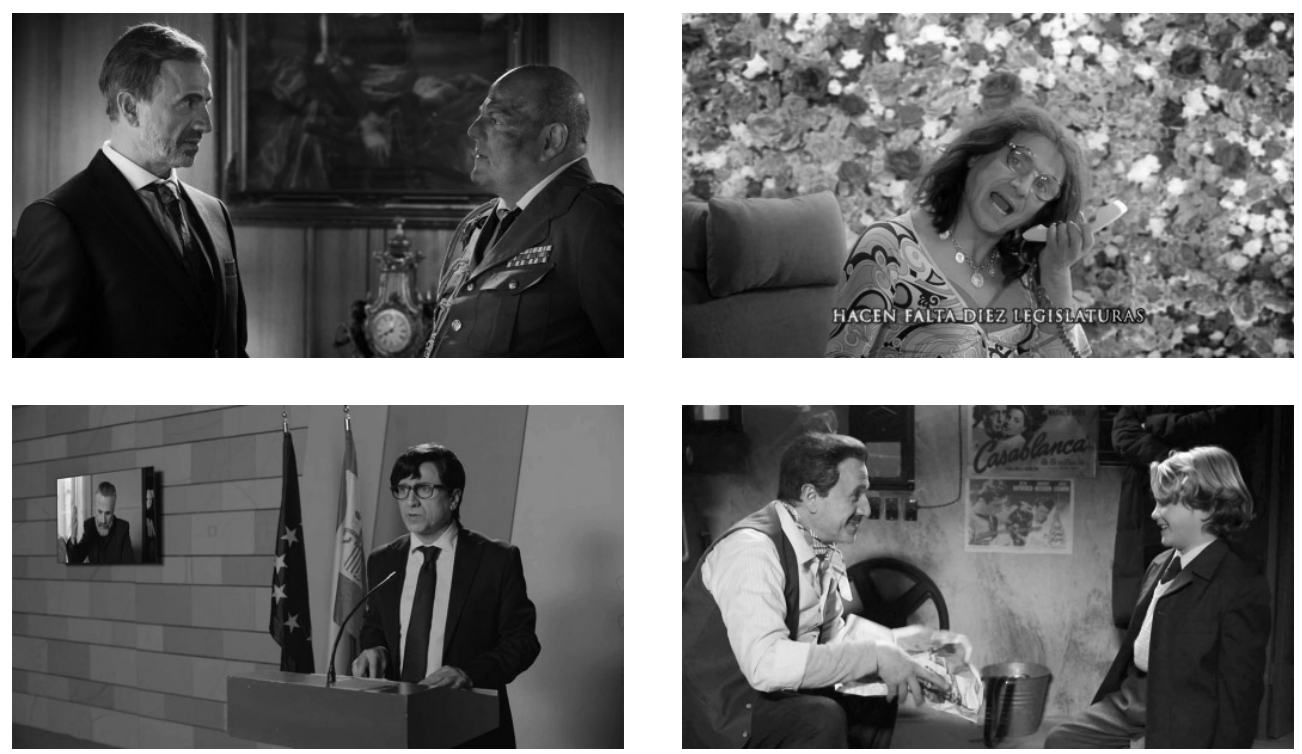

Fuente: RTVE.

Figuras 2, 3, 4 y 5

José Mota caracterizado como el Rey Felipe VI y de Rosalía en el especial 2019 y del ministro Salvador Illa y como parodia de Cinema Paradiso en 2020

Para finalizar, se constata que los efectos visuales se muestran en más del 74\% de las unidades analizadas en ambos casos, escasos puntos más en 2020. Una cifra mayoritaria, pero que refleja que, prácticamente, un cuarto de los espacios no incluye efectos visibles o representativos. Asimismo, se prueba que los recursos humorísticos son dispares, como queda reflejado en el siguiente gráfico, destacando el 
empleo de música, efectos especiales y rótulos en similares porcentajes y, por el contrario, doblajes, hemeroteca en disparidad sobre ambas ediciones.

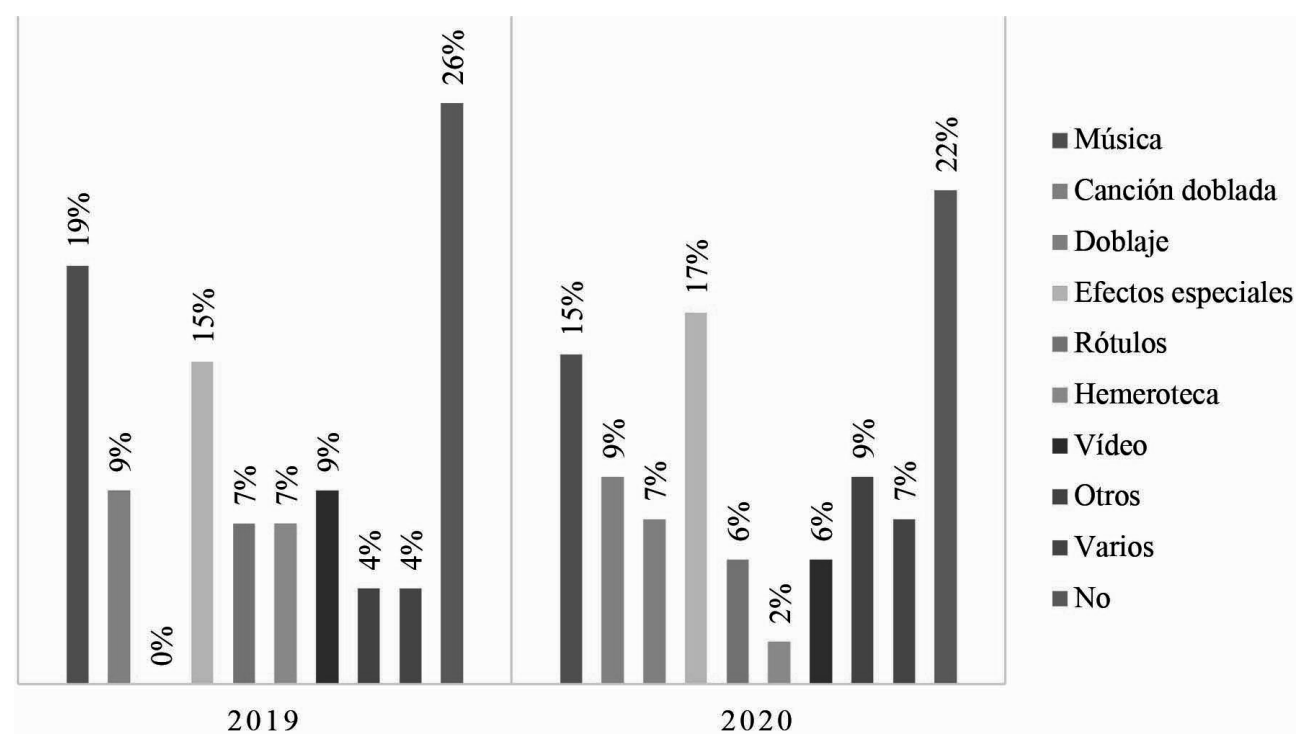

Fuente: elaboración propia.

GrÁFICO 4

Diferentes recursos visuales de los especiales de humor

\section{Discusión}

Se confirma que los especiales son un infoshow adscrito a la tipología de programa de sketches humorísticos por la prevalencia de imitaciones de personajes famosos, así como la parodia de programas televisivos o secuencias cinematográficas (Gordillo, 2009). Tras esta primera consideración, desde el análisis se extrapola la importancia de las imitaciones de personajes famosos y el especial realismo con el que se han realizado, tanto de forma física - vestuario, caracterización y maquillaje - como de doblaje, un especial cuidado de las imitaciones que era alentado por Arroyo (2008). También, al mismo tiempo, se comprueba que estos sketches parten de una premisa divertida (Erre, 2019).

Igualmente se comparte la participación de invitados; pero solo en el primer especial con la preponderancia de humoristas mediáticos apuntada por Diego y Grandío (2011) que destacaban su grabación en exteriores, como también se ha podido contrastar, en el segundo, así como el hecho añadido por estos autores de que este 
tipo de programas suele programarse en horario de máxima audiencia. Una idea que queda ampliada hasta conferir una fecha especial anual y reiterativa.

Se confiere pues que son recurrentes y que generan innovaciones (Gordillo, 2009), ya que, como sentencia San José (2008), el humor televisivo se ha escrito con sketches, siendo un modelo no novedoso, pero tampoco caduco. Asimismo, de forma pareja a lo relatado, se puntualiza, como determina Medina (2006), el entretenimiento suele estar relacionado con el humor, el talento y la innovación.

En otro orden de temas, en cuanto al humor y la actualidad se conoce que se debate desde hechos coetáneos, reales y presentes que generan interés y atención del público (Puebla-Martínez, 2013) contrastada, en este mismo sentido, con las problemáticas ciudades y los temas que nutren los medios de comunicación, vislumbrando como hecho que los problemas reflejados por la sociedad en las noticias sí son una fuente importante, inagotable para las premisas del sketch, como defendía (Erre, 2019).

Una vía complementada con la aportación de cómo este formato ha instruido la pandemia COVID-19 en su escaleta humorística, otorgándole una importante parte de la actualidad narrada e incluso soslayando su principal cometido a homenajear a sus principales víctimas, las personas mayores. Con el apoyo de los primeros avances de recientes estudios como los de Andueza et al. (2020) que constatan un ejemplo de transformación televisa por la crisis sanitaria de la COVID-19 o que la diversidad puede ser enfrentada desde el humor (Balarezo-López, 2020), se apuesta desde estas líneas por el argumento del humor como herramienta que canaliza emociones y ofrece esperanza, citado por Sola-Morales (2020) sobre Ernst Bloch (2007). Una vía de escape sin olvidar la realidad, manifestada desde el especial de Nochevieja de 2020 por José Mota.

Sola-Morales (2020) también afianza, al igual que nuestros resultados, que la ironía y la parodia son parte de un humor en confinamiento que pretende hacer reflexionar. Un humor como mecanismo para afrontar el escenario que hemos enfrentado de forma mundial (Torres et al., 2020). Un humor que en una noche especial no deja de lado la realidad, aunque la comedia sea su baza principal.

\section{Conclusiones}

Se reconoce que en ambos especiales predomina un cometido inicial y temático, mientras que los problemas de la ciudadanía son abordados en parte de sus sketches como complemento al hilo argumental. Que, primero, en 2019 fue la defensa de la comedia y a la libertad de expresión ejercida por los profesionales del humor, los que intervienen en sketches y escenificaciones, y que, después, en 2020, se trató 
de un homenaje a la película «Cinema Paradiso» con la que subrayar la figura y la superación de los mayores ante la pandemia.

De esta forma, se confiere que la actualidad no es el tema principal del especial 2019, ya solo acapara el 30\% los espacios que lo componen, el cual circula sobre el eje temático del humor, pero, debido a la situación excepcional derivada de la COVID-19, sí que el especial 2020 apuesta por la actualidad en el 48\% del total de su escaleta. Un incremento notable.

Por lo tanto, pese a comprobar que las problemáticas sociales no son mayoritarias en el guion, sí se ha probado que las inquietudes mostradas por los ciudadanos en la encuesta del CIS como el paro o la política o la pandemia forman parte Del contenido de estos especiales. Al mismo tiempo, se descubre que los temas observados incluyen otras preocupaciones sociales no recogidas por este índice, pero de relevancia mediática como el cambio climático, la censura social o el odio, por ejemplo. De este modo, se concluye que los contenidos de los sketches contienen un humor irónico, absurdo y una crítica de la actualidad que cuestiona y trabaja la información sobre política o sociedad aportando una visión periodística desde el humor, siempre de la mano de las principales noticias del año y con una finalidad cómica.

En cuanto a conclusiones de estructura, ambos especiales se identifican con los recursos de caracterización unidos a la imitación de los principales protagonistas de la actualidad, junto a la parodia de programas de televisión y películas. Por lo tanto, tras su análisis, se responde afirmativamente la segunda pregunta del presente artículo, dado que su estructura dispone de múltiples y diferentes recursos humorísticos y visuales fundamentados en imitaciones y caracterizaciones rodados en cromas y exteriores gracias a efectos especiales y música, como principales reseñas.

Por lo tanto, esta diversidad estética y humorística reiterativa es coincidente con lo acontecido cada año para la sociedad española conformando, a su vez, las claves de contenido y estructura ligadas a la actualidad y excedidas por la comedia. Todo, desde un especial de humor avalado a lo largo de las últimas décadas por altas y continuadas cifras de audiencia y por la ya programación histórica en el canal público TVE.

\section{Referencias bibliográficas}

Aguilera, I. C. (2019). La cultura del humor televisivo: el infoentretenimiento español desde su utilidad para las audiencias. ZER-Revista de Estudios de Comunicación, 25(47), 31-50. http://doi.org/d6hs 
Aguilera, I. C. (2020). Actualidad y comedia: El éxito de El Intermedio y La Resistencia entre los espectadores jóvenes. Ámbitos. Revista Internacional de Comunicación, 50, 80-95. https://doi.org/10.12795/Ambitos.2020.i50.06

Andueza, B; Santana, S. y de Luis Otero, A. M. (2020). Transformación de la realización y adaptación de los contenidos de los programas de televisión late night del canal \#0 de Movistar Plus. El caso de Late Motiv, La Resistencia y LocoMundo durante la crisis de la COVID-19 en España, del nueve de marzo al veintiséis de mayo de 2020. Revista Inclusiones, 8( $\mathrm{n}^{\mathrm{o}}$ especial), 165-196

Antona, T. (2017). El entretenimiento como pilar de la programación televisiva durante el periodo 1958-75. Communication \& Society, 30(2), 31-45.

Amici, P. (2020). Humor in the age of covid-19 lockdown: an explorative qualitative study. Psychiatria Danubina, 32, 6.

Arana, E. (2011). Estrategias de programación televisiva. Madrid: Síntesis.

Arroyo, E. (2008). El infotainment. De Caiga Quien Caiga a Noche Hache. In A. Sangro y P. Salgado (eds.), El entretenimiento en TV: Guion y creación de formatos de humor (pp. 173-192). Barcelona: Laertes.

Balarezo-López, G. (2020). Reír para no sufrir: la pandemia del coronavirus a través del humor de los memes en el WhatsApp. Paideia XXI, 10(2), 18. https://doi.org/ doi:10.31381/paideia.v10i2.3444

Barlovento Comunicación (2020). Audiencias jueves 31 de diciembre de 2020. Recuperado de https://bit.ly/3cGPriu

Barlovento Comunicación (2021). Audiencia Campanadas 2020. Recuperado de https://bit. ly/2YGFZDh

Berger, P. (1999). La risa redentora. La dimensión cómica de la experiencia humana. Barcelona: Kairós.

Berger, A. A. (2017). An anatomy of humor. Routledge (publicado en 1993).

Bluper (2020). Audiencias: Mota vuelve a reinar en Nochevieja y «Cachitos» pega fuerte. El español. Recuperado de https://bit.ly/3gR9aei

Bonaut, J. (2008). La influencia de la programación deportiva en el desarrollo histórico de TVE durante el monopolio de la televisión pública (1956-1988). Communication \& Society, 21(1), 103-136.

Bonaut, J. y Gascón-Vera, P. (2020). Estrategias de construcción del humor en el infoentretenimiento televisivo: Análisis del caso de los "vídeos manipulados» de El Intermedio durante la crisis del Covid-19. Congreso Sociedad Española de Periodística. https://bit.ly/3rnTSTx

Buenafuente, A. (Ed). (2011). Lo que vendría a ser la televisión en España según Buenafuente y El Terrat. Barcelona: Editorial Planeta.

Carpio, J. A. (2008). El humor en los medios de comunicación: estudio de Los Guiñoles y sus efectos en las opiniones politicas. (Tesis doctoral, Universidad Pontificia de Salamanca).

Casado, M. (2017). Historias de la Tele. Barcelona: Aguilar.

Cascajosa, C. (2016). La televisión en Europa. En C. Cascajosa y F. Zahedi, Historia de la televisión (pp. 21-86). Valencia: Tirant lo Blanch. 
Centro de Investigaciones Sociológicas CIS (2019). Barómetro de noviembre 2019. Estudio n³267. https://bit.ly/2DKcR7s

Centro de Investigaciones Sociológicas CIS (2020). Barómetro de noviembre 2020. Estudio n³300 https://bit.ly/39DeWiF

Contreras, J. M. (2008). Prólogo. En P. Sangro y A. Salgado (eds), El entretenimiento en TV: Guion y creación de formatos de humor en España (pp. 19-22). Barcelona: Laertes.

Contreras, J. M. y Palacio, M. (2003). La programación en televisión. Madrid: Síntesis.

Cuenca-Piqueras, C., y Moreno, M. J. G. (2018). Ensayo: desde Sabrina a Cristina Pedroche. Reflexiones sobre la imagen femenina en la televisión durante las campanadas. RAUDEM. Revista de Estudios de las Mujeres, (5), 277-281.

Díaz Herrera, C. (2018). Investigación cualitativa y análisis de contenido temático. Orientación intelectual de revista Universum. Revista general de información y documentación, 28(1), 119. http://dx.doi.org/10.5209/RGID.60813

Diego, P. y Grandío M. ${ }^{a}$ del M. (2011). Clasicismo e innovación en la producción nacional de comedia televisiva en España (2000-2010). Revista Comunicación, 1(9), 49-66.

Diego, P., y Grandío, M. ${ }^{a}$ del M. (2014). Producción y programación de series cómicas de TVE en la época franquista: Jaime de Armiñán y las primeras comedias costumbristas. Estudios sobre el Mensaje Periodístico, 20, 105-120.

Erre, F. (2019). Cómo tener éxito escribiendo sketches. Madrid: Laertes.

Fernández Flórez, W. (1945). El humor en la literatura española. Madrid: Sáez-Buen suceso.

Fernández Gómez, E. (2012). La programación infantil y juvenil de la televisión pública española: ¿oferta generalista o temática? El paso de La 2 a Clan TVE. Estudios sobre el mensaje periodístico, 18 (Núm. especial octubre), 313-323.

García-Avilés, J. A. (2004). Distorsiones de la realidad en la neotelevisión. El pseudoperiodismo satírico y el periodismo de entretenimiento como subgéneros del info-show. In N. Mínguez y N. Villagra. (Eds.), La comunicación nuevos discursos y perspectivas (pp. 37-45). Madrid: Colección Comunicación Edipo.

Gascón-Vera, P. (2019). «El Informal», el doblaje y su programación en «access prime time» como ejes del éxito televisivo de un formato periodístico de humor. Index.comunicación, 9(3), 139-163.

Gascón-Vera, P. (2020). El infoentretenimiento en la televisión de pago, Movistar+ y el canal \#0. El uso transmedia de sus contenidos de humor. Ámbitos. Revista Internacional de comunicación, 49, 177-196. https://doi.org/10.12795/Ambitos.2020.i49.11

Gascón-Vera, P. y Torres, J. L. (2020). Los especiales de humor de fin de año en televisión. Estudio de caso de José Mota en TVE: Estructura, tratamiento de la actualidad y traslación vía Twitter. Congreso Sociedad Española de Periodística, Zaragoza. https://bit.ly/3cvtSRN

Gascón-Vera, P. y Marta-Lazo, C. (2018). Formatos al servicio del sketch: Oregón TV, Polònia y Vaya Semanita. El infoentretenimiento en las televisiones autonómicas españolas. In B. Puebla-Martínez, E. Del campo y R. Gelado-Marcos. Sinergias digitales: hibridaciones entre información, ficción y entretenimiento (pp. 195-216). Egregius Ediciones. 
Gascón-Vera, P, y Marta-Lazo, C. (2019). Estructura y escenografia de los formatos periodísticos de humor del access prime time 2018-2019. Estudio comparativo entre Lo Siguiente, Ese programa del que usted me habla, El Hormiguero y El Intermedio. Textual \& Visual Media (12).

Gibbs, G. (2012). El análisis de datos cualitativos en Investigación Cualitativa. Ediciones Morata.

Gómez Rodríguez, G. M. (2020). La realidad en la ficción: Las preocupaciones de los españoles en las series de televisión (1990-2010). (Tesis doctoral. Universidad Complutense de Madrid).

Gordillo, I. (2009). Manual de narrativa televisiva. Madrid: Editorial Síntesis.

Gordillo, K. (2020). José Mota gana el juicio contra la constructora de su casa tras cuatro años de batalla legal. Elmundo.es. Recuperado de https://bit.ly/2DVi2Sf

Guerrero, E. (2010). El entretenimiento en la televisión española. Historia, industria y mercado. Barcelona: Deusto-Grupo Planeta.

Hussein, A. T., y Aljamili, L. N. (2020). COVID-19 humor in Jordanian social media: A socio-semiotic approach. Heliyon, e05696.

Krippendorff, K. (1990). Metodología de análisis de contenido. Teoría y práctica. Paidós Comunicación.

Krüger, U. M. (1988). Infos- Infotainment- Entertainment? Media Perspektiven, 10, 637-664.

Luzón, V., \& Ferrer, I. (2008). Espectáculo informativo en noticias de sociedad: el caso de Madeleine McCann. Trípodos, 22, 137-148.

Mancero, J. B., Naranjo, C. L., y Parreño, R. R. (2020). Tratamiento del Covid-19, Ecuador mediante el humor periodístico/Tratamento de Covid-19, Equador através do humor jornalístico. Brazilian Journal of Health Review, 3(2), 3523-3541.

Martín-Sánchez, D. (2020). La comedia de situación y su análisis textual: evolución de los elementos constructivos del formato. Ámbitos. Revista Internacional de Comunicación, 47, 238-266.

Medina, M. (2006). Calidad y contenidos audiovisuales. Pamplona: Eunsa.

Meléndez-Malavé, N. (2005). El humor gráfico en el diario El País durante la transición política española (1976-1978). (Tesis doctoral, Universidad de Málaga).

Méndez, E. (2004). Humor y televisión en España. In P. Merlo y B. Riesgo (eds.), Lhumour hispanique (pp. 147-190). Lyon: Université Lyon II.

Merchán, E. R. (2014). Antecedentes, orígenes y evolución de un programa mítico: Estudio 1 de TVE. Estudios sobre el mensaje periodístico, 20, 267-79.

León, B. (2008). Introducción. Televisión de calidad frente a «telebasura». En B. León (coord), Otra televisión es Posible (pp, 13-21). Comunicación Social.

Pedrero, L. M. (2008) Armas de seducción catódica: Los géneros de entretenimiento en la neo televisión contemporánea. In P. Sangro y A. Salgado, A. (eds.), El entretenimiento en TV: Guion y creación de formatos de humor en España (pp.33-54). Barcelona: Laertes.

Pérez Pereiro, M. (2007). Modalidades humorísticas na comedia televisiva galega, humor e ideoloxía na fórmula televisiva da comedia de situación. (Tesis doctoral, Universidad de Santiago de Compostela). 
Pinto, M. R. (1991). La influencia del humor en el proceso de la comunicación. (Tesis Doctoral, Universidad Complutense de Madrid).

Prado, E., y Delgado, M. (2010). Tendencias internacionales de programación. Telos, 84, $52-64$.

Puebla-Martínez, P. (2013). El tratamiento de la actualidad en las series de ficción. Los casos de 7 vidas $y$ de Aquí no hay quien viva (2004-2006). (Tesis Doctoral, Universidad Rey Juan Carlos).

Quintas-Froufe, N. (2018). El ocaso de la televisión pública española ante su audiencia: un lustro decadente (2010-2015). Palabra clave, 21(1), 3.

Redondo, M., y Campos-Domínguez, E. (2015). Implicaciones éticas del infoentretenimiento televisivo. Comunicació: Revista de Recerca i dÀnàlisi, 32(1), 73-89.

Roel, M. (2014). Audiencia y programación en Televisión Española: del ocaso del modelo paleotelevisivo al umbral del neotelevisivo. Estudios sobre el Mensaje Periodístico, (20), 157.

Romero-Rodríguez, L., Moreno, P. D. C., y Toukoumidis, Á. T. (2015). Estereotipos, tópicos y lenguaje de la programación sensacionalista en la televisión: programa «Corazón» de TVE. Alteridad, 10(1), 31-43.

Salgado, A. (2010). Actualidad, humor y entretenimiento en los programas de televisión: de la terminología a la realidad profesional. Trípodos, 27, 59-73.

San José, D. (2008) En Ocasiones... bebo mosto. El caso de Vaya Semanita. In P. Sangro y A. Salgado (eds.), El entretenimiento en TV: Guion y creación de formatos de humor en España (pp. 239-250). Barcelona: Laertes.

Sánchez, M. (2010). Humor se escribe con hache: Una propuesta didáctica para la explicación del léxico en la clase de ELE. marcoELE. Revista de Didáctica Español Lengua Extranjera (10), 1-11.

Sebastián, J. M. V. (2011). ¡Atrápalos como puedas!: la competencia televisiva: programación y géneros. Valencia: Tirant lo Blanch.

Sola-Morales, S. (2020). Humor en tiempos de pandemia. Análisis de memes digitales sobre el coronavirus. ZER-Revista de Estudios de Comunicación, 25(49), 35-58. https://doi. org $/ 10.1387 /$ zer. 21817

Torres, J. M., Collantes, L. M., Astrero, E. T., Millan, A. R., y Gabriel, C. M. (2020). Pandemic Humor: Inventory of the Humor Scripts Produced during the COVID-19 Outbreak. SSRN Electronic Journal. https://doi.org/10.2139/ssrn.3679473

Trabadela-Robles, J. y Corral-Motino, D. J. (2021). Canales de vídeo de doblaje paródico en YouTube en España. Los casos de Loulogio, Desahogada, Korah, Keunam y HDub. Dígitos. Revista de Comunicación Digital, 7.

Valhondo, J. L. (2007). Infosátira y democratización del espacio televisivo. Quaderns del CAC. Imagen y derecho a la burla (27), 63-71.

Valhondo, J. L. (2011). Sátira televisiva y democracia en España. La popularización de la información política a través de la sátira. Barcelona: Editorial UOC. 